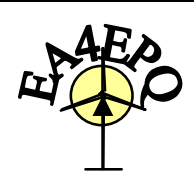

\title{
Synthetic Ester-Based Oils and Their Application in Power Industry
}

\author{
V. Mentlík, R. Polanský, P. Prosr, J. Pihera and P. Trnka \\ Department of Technologies and Measurement \\ Faculty of Electrical Engineering, University of West Bohemia in Pilsen, \\ Univerzitní 26, 30614 Pilsen, Czech Republic, \\ Phone: +420377634 517, e-mail: mentlik@ket.zcu.cz, rpolansk@ket.zcu.cz, \\ prosr@ket.zcu.cz, pihera@ket.zcu.cz, pavel@ket.zcu.cz
}

\begin{abstract}
Suitable (biodegradable) substitution of classic mineral petroleum-based oils used in power transformers is studied. Paper presents test results of six paper-oil insulation systems varying by different type of oil. Three common transformer oils and three new synthetic oils (never used in power transformers before) were selected for the purpose of experiment. The oils have been exposed to accelerated thermal aging (at the temperature of $90{ }^{\circ} \mathrm{C}$ ) and their properties were measured in time intervals of $0,50,125,225,500,1000$ and 2000 hours.
\end{abstract}

\section{Key words}

Power transformer, synthetic oils, biodegradable oils, loss factor, insulating resistance, polarization index, infrared spectroscopy.

\section{Introduction}

The power transformer insulation system is combined of oil and solid cellulose paper. Many papers have been already focused on study of such combined insulation system of transformer [1]-[3]. As generally known, liquid component of electrical insulation expressively influences final properties of the whole insulation system. Nowadays the attention is given mainly to application of ecological materials. This trend to substitute the petroleum-based oils by more ecological insulating oils is observed also in the problems of oil filled transformers [4]-[6]. Synthetic or vegetable oils are considered to be suitable variants of such substitution.

The usage of suitable (biodegradable) insulating oils would expressively improve the ecological aspects of all power transformers operation. This premise stands in the basis of the main aim of this paper, which is to investigate the possibilities of substitution of the petroleum-based oils by suitable synthetic or natural product.

Project is based on testing of six oils (3 common petroleum-based oils and 3 synthetic esters-based oils).
Oils were exposed to accelerated thermal aging and their properties were monitored in predefined intervals (the electrical test methods as well as the infrared spectroscopy and some thermal analyses were used). Some of the test results have been already presented [7]-[11].

The objective of this paper is to summarize obtained data in complex way and compare the behavior of tested oils along the accelerated thermal aging. Considering the fact that tested synthetic oils are not used as the insulating liquids in power transformers in the meanwhile, their properties are compared to mentioned petroleum-based oils.

\section{Experimental}

\section{A. Oils and cellulose paper description}

As noted previously, two groups of insulating oils (see Table I) were chosen for the purpose of the experiment. Three kinds of mineral petroleum-based oils are in the first one (tested only for comparison); the second group contains three quite new oils based on synthetic esters.

TABLE I. - Tested Insulation Liquids

\begin{tabular}{|c|c|}
\hline Petroleum-based oils & Synthetic oils \\
\hline M1 & DBP (Dibutyl phthalate) \\
\hline M2 & DOA (Dioctyladipate) \\
\hline M3 & DIBA (Diisobutyl adipate) \\
\hline
\end{tabular}

Specification of synthetic oils is as follows:

Dibutyl phthalate (DBP) - dibutyl ester of phthalic acid - it is colorless or slightly yellow viscous liquid, stable at ordinary physical-chemical conditions. This substance decomposes and toxic combustion products release after the boiling point $\left(340^{\circ} \mathrm{C}\right)$ exceeding and at burning process as well. DBP is suitable to products for industrial purpose only. 
Dioctyladipate (DOA) - di(2-ethylhexyl) ester of adipic acid - it is colourless or slightly yellow viscous liquid and it isn't classified as a dangerous substance. DOA is considered to be biodegradable substance without any negative effects on environment.

Diisobutyl adipate (DIBA) - bis(2-methylpropyl) ester of adipic acid - it is also colorless or slightly yellow substance without any negative effects on environment. It is stable at ordinary physical-chemical conditions and it isn't classified as a dangerous substance.

Currently common transformer board was used as paper component. The cellulose paper samples (size of $10 \times 10$ $\mathrm{cm}$, thickness of $0,5 \mathrm{~mm}$ ) were sank into these oils to create the transformer oil-paper insulation system and provide the real experimental conditions.

\section{B. Thermal exposure}

Oil-paper samples were subjected to accelerated thermal aging at the temperature of $90{ }^{\circ} \mathrm{C}$ up to 2000 hours.

\section{Electrical characteristics}

Selected electrical characteristics were observed during thermal aging of oil-paper insulation system: loss factor $\operatorname{tg} \delta$, capacity $\mathrm{C}(\mathrm{pF})$, permittivity $\varepsilon$, minute polarization index $\mathrm{p}_{\mathrm{i}}$ and volume resistance $\mathrm{R}(\Omega)$. Measuring of all characteristics proceeded at the times of: $0,50,125,225$, 500,1000 and 2000 hours of thermal aging.

Three-electrode system was used for measurement of electrical characteristics, when paper sample was sunk into tested oil and created demanded insulation system (see Fig. 1). Measurement frequency was set to 10 samples and average value has been calculated.

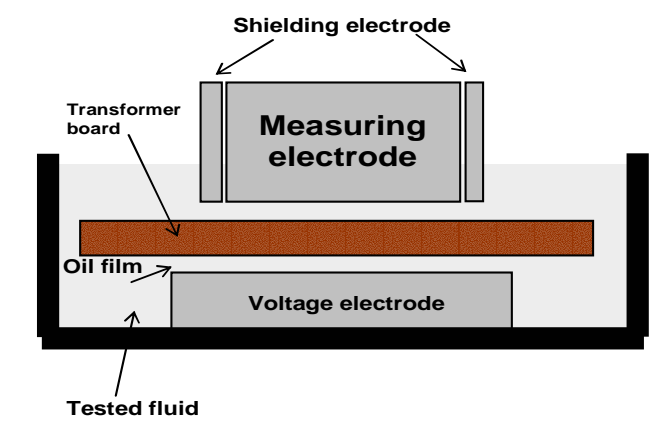

Fig. 1. Measurement of the electrical characteristics of the oil-paper system (cross-section of measuring system).

\section{FT-IR spectroscopy}

Technique of Attenuated Total Reflectance was used during the measurement via Fourier Transform Infrared Spectroscopy. This method is very suitable especially for measuring of spectra of liquid samples, which intensely absorb the infrared radiation. Technique is based on principle of multiple total reflection of radiation on sample-crystal interface (crystal made of material with high refractive index).
Infrared spectra were collected on a Nicolet 380 FT-IR spectrometer and averaged over 32 scans with a resolution of $4 \mathrm{~cm}^{-1}$. The spectrometer was purged with dry air. Many crystals of different materials e.g. ZnSe, $\mathrm{AgCl}, \mathrm{Si}, \mathrm{Ge}$, sapphire or KRS-5 (thallous bromideiodide) can be used for the purpose of the measurement. In our case crystal DTGS $\mathrm{KBr}$ was applied and OMNIC software was consequently used for display and analysis of collected spectra.

ATR analysis has been performed meanwhile on one oil from each group of insulating liquids (DOA as synthetic oil and M2 as petroleum-based oil) at virgin state and after 500, 1000 a 2000 hours of thermal aging.

\section{Results}

\section{A. Electrical characteristics}

The Fig. 2 illustrates the trend of insulating resistance in dependence on time of thermal aging. Difference of the measured resistances for synthetic and petroleum-based oils is obvious. All petroleum-based oils show very similar trend of insulating resistance. The decreasing trend of the resistance of the synthetics oils corresponds to the starting point of the degradation process. Remarkable lower resistance is observed on the samples with DBP oil.

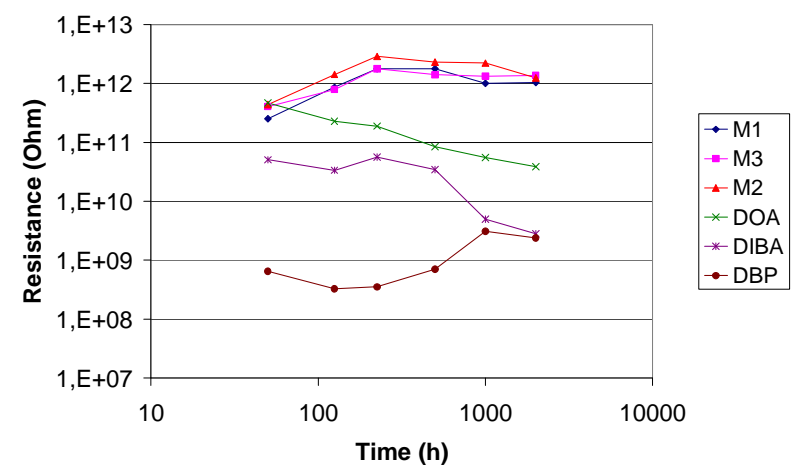

Fig. 2. Insulating resistance time dependence in logarithmic scale.

Fig. 3 shows the results of loss factor measurement. Petroleum-based oils show again very similar properties, synthetic oils on the other hand differ from each other. The worst results (i.e. the highest values of loss factor) were obtained in measurement with synthetic DBP oil ( $\tan \delta$ up to 0,4$)$. Petroleum-based samples have loss factor $\tan \delta 0,01$. Loss factor of DOA oil after 2000 hours is about 0,07 . 


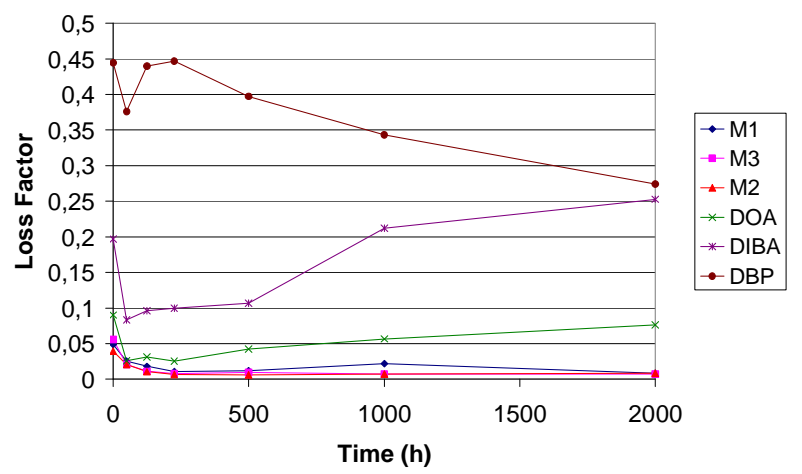

Fig. 3. Loss factor time dependence.

The results of the polarization index evaluation are presented in Fig. 4. Increasing trend of the polarization index on the beginning of thermal aging is evident. This fact can be explained by slight desiccation of tested liquids and paper as well. The polarization index of all petroleum-based oils and DOA synthetic oil is generally higher than in case of DIBA and DBP oils.

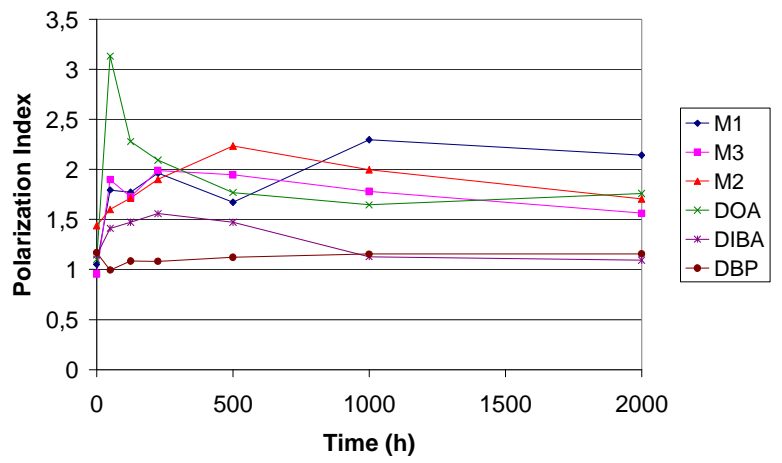

Fig. 4. Evaluated Polarization index.

\section{B. FT-IR spectroscopy}

M2 and DOA oils were also tested by FT-IR spectroscopy, via ATR technique respectively. As said before, this analysis was performed on samples in virgin state and after 500, 1000 and 2000 hours of thermal aging.

Fig. 5 presents the FT-IR spectra of virgin M2 oil. Spectral bands of 3000 and $1460 \mathrm{~cm}^{-1}$ correspond to hydrocarbons, band in $800-712 \mathrm{~cm}^{-1}$ region is characteristic for degree of refining process.

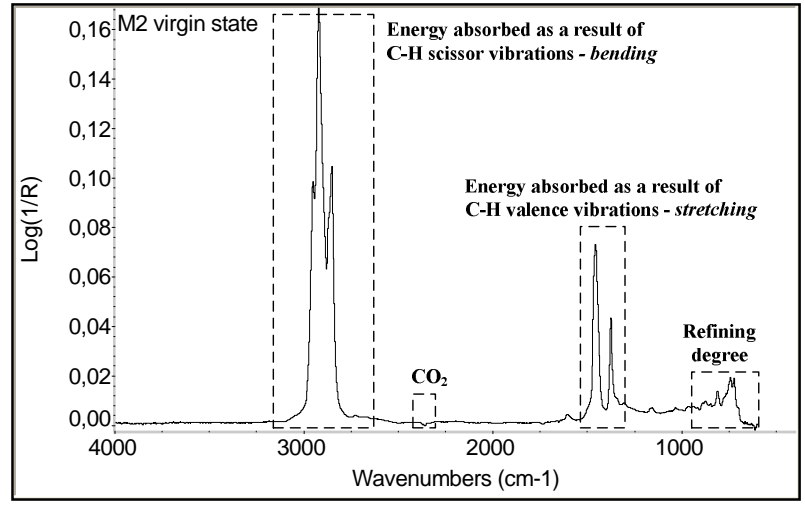

Fig. 5. FT-IR spectra of virgin M2 oil.
No marked changes in spectra of M2 oil were observed owing to applied thermal aging, only slight differences were recorded in $\mathrm{CO}_{2}$ band $\left(2361 \mathrm{~cm}^{-1}\right)$, where its intensity increased in the beginning (between virgin state and 1000 hours of aging) with longer time of thermal aging (see Fig. 6).

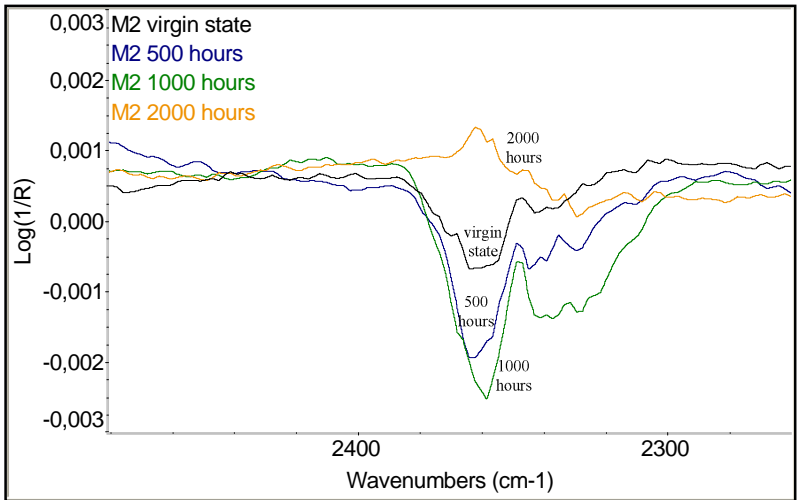

Fig. 6. $\mathrm{M} 2$ oil - detail of $\mathrm{CO}_{2}$ spectral band $\left(2361 \mathrm{~cm}^{-1}\right)$.

Following figure (Fig. 7) presents the spectral bands of virgin synthetic DOA oil.

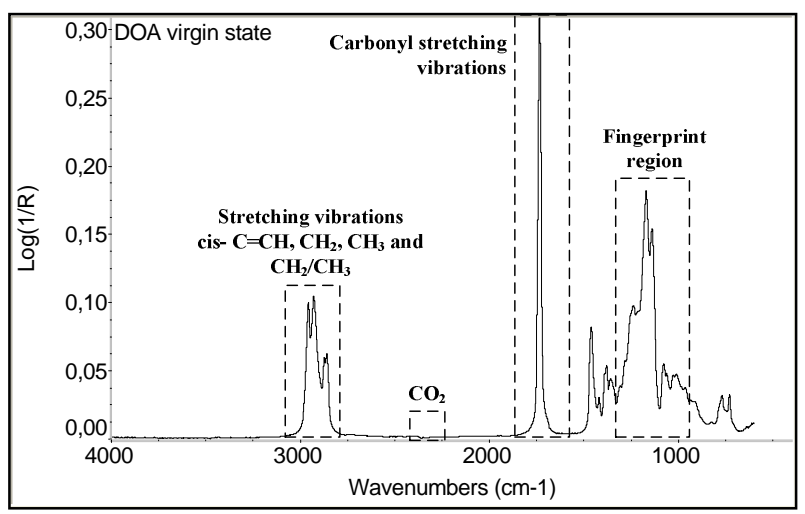

Fig. 7. FT-IR spectra of virgin DOA oil.

When we focus on spectra interpretation, there are bands pertaining to stretching vibrations of cis- bonds $\mathrm{C}=\mathrm{CH}$, $\mathrm{CH}_{2}, \mathrm{CH}_{3}$ and $\mathrm{CH}_{2} / \mathrm{CH}_{3}$ in $3050-2800 \mathrm{~cm}^{-1}$ region. Compared to mineral M2 oil, the strong spectral band of $1735 \mathrm{~cm}^{-1}$ is evident here, which corresponds to vibration of triglyceride ester carbonyl group (carbonyl CO stretching vibrations).

There are mainly absorption bands of so called fingerprint region in frequency range of 1000 and 1300 $\mathrm{cm}^{-1}$. It is one of characteristic spectral regions, where symmetry of vibrations is very complicated and final absorption spectrum is characteristic for the whole molecules or their major groups (ester group in this case).

Decrease of intensity of $1736 \mathrm{~cm}^{-1}$ carbonyl band and increase of another carbonyl band of $1712 \mathrm{~cm}^{-1}$ was recorded in DOA oil owing to applied thermal aging, as obvious in Fig. 8. 


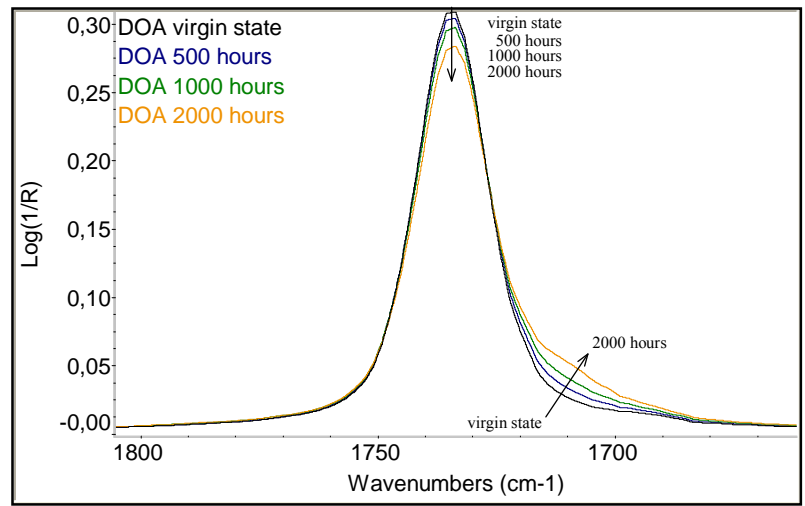

Fig. 8. DOA oil - detail of 1736 a $1712 \mathrm{~cm}^{-1}$ carbonyl bands.

Decreases were observed also in bands of 2960 and $2930 \mathrm{~cm}^{-1}$ (C-H stretching vibration) and in band of $1169 \mathrm{~cm}^{-1}$ (probably deformation O-C-O bond) - see Fig. 9 and 10. On the other hand, increases were recorded in $3400-3100 \mathrm{~cm}^{-1}$ region $(\mathrm{O}-\mathrm{H}$ stretching vibration) and in band of $1284 \mathrm{~cm}^{-1}$ - see Fig. 11 and 12 .

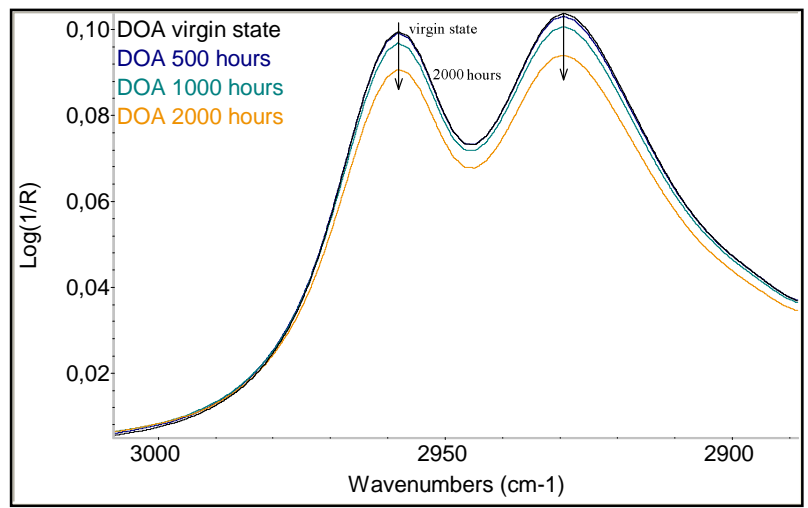

Fig. 9. DOA oil - detail of 2960 and $2930 \mathrm{~cm}^{-1}$ spectral bands.

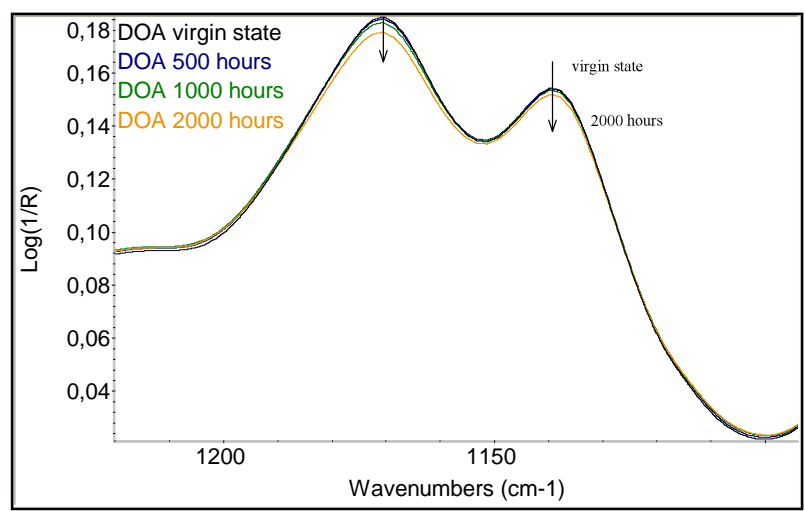

Fig. 10. DOA oil - detail of $1169 \mathrm{~cm}^{-1}$ spectral band.

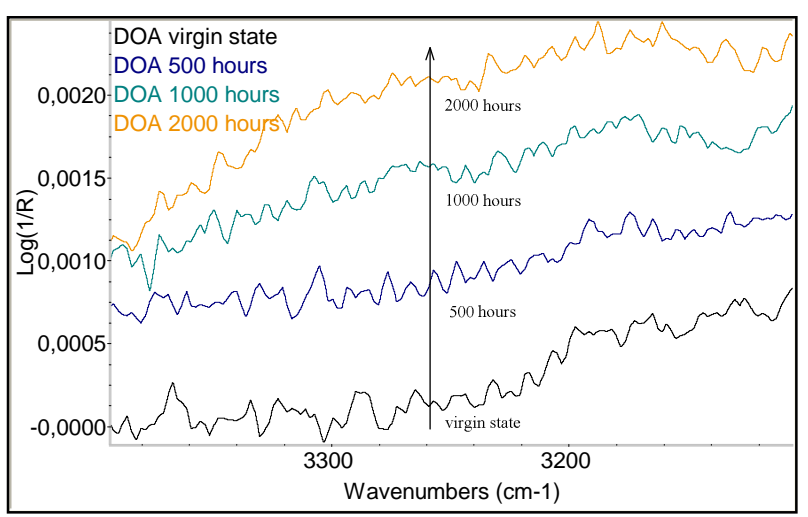

Fig. 11. DOA oil - detail of $3400-3100 \mathrm{~cm}^{-1}$ spectral region.

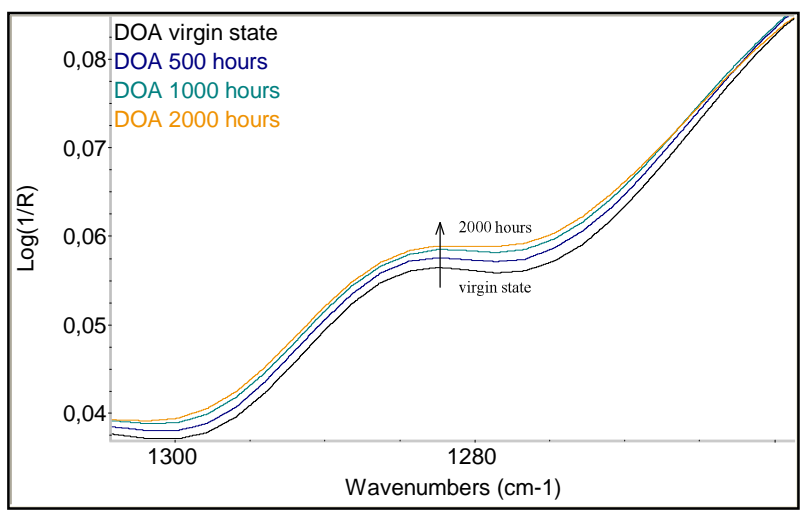

Fig. 12. DOA oil - detail of $1284 \mathrm{~cm}^{-1}$ spectral band.

All described trends point at decomposition of primary ester to another compound(s) also containing ester group. The presence of strong band of $\mathrm{O}-\mathrm{H}$ stretching vibration $\left(3400-3100 \mathrm{~cm}^{-1}\right.$ region) corresponds either to water creation during the degradation or to carboxylic acid creation during the hydrolysis of primary ester.

General spectra differences of tested samples (mineral and synthetic oil) are illustrated in figure 13, where IR spectrum of both M2 oil and synthetic DOA oil is shown. Single spectra are very similar in many respects. They differ mainly in the intensity of identical bands (hydrocarbons and $\mathrm{CO}_{2}$ ) and also in presence of strong spectral band corresponding to oxidation $\left(1700 \mathrm{~cm}^{-1}\right)$ and spectral band of $1171 \mathrm{~cm}^{-1}$ in the case of synthetic insulating oil.

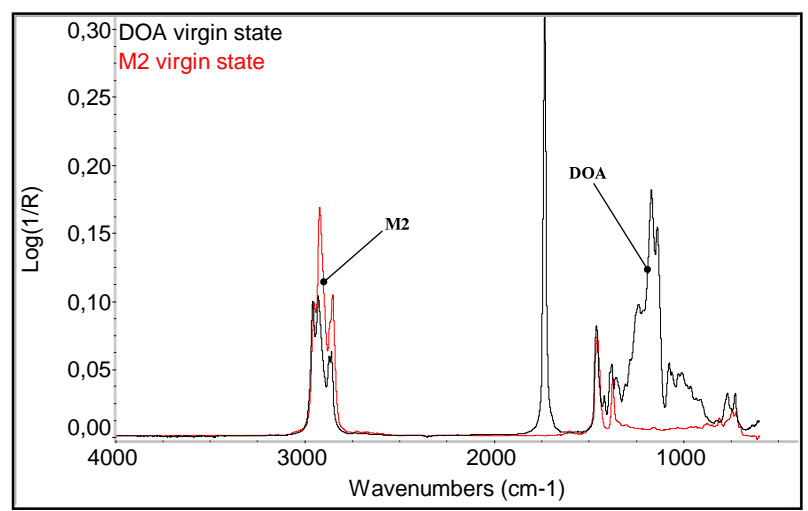

Fig. 13. Comparison of DOA and M2 FT-IR spectra. 
As we compare FT-IR results of tested oils, markedly worse oxidative stability of synthetic oil is evident. This is supported by spectral band of $1735 \mathrm{~cm}^{-1}$ corresponding to oxidation (caused by valence vibration of carbonyl $\mathrm{C}=\mathrm{O}$ group). Insufficient oxidative stability of this oil in operation would lead to carbonyl sludge creation, to acceleration of corrosion and to decrease of whole transformer service life.

Besides presented changes of DOA oil sample (Fig. 812), no expressive changes of obtained spectra were observed in the whole time interval of aging $(0-$ 2000 hours). This can be caused by unexpended inhibitor of mineral oil and higher thermal resistance of synthetic oil (proved also by thermogravimetry before) [9].

\section{Conclusion}

The results of the experiment demonstrate the differences between the insulation systems containing petroleumbased oils and synthetic oils. Measurements proved that synthetic oil samples don't reach as good properties as samples containing petroleum-based oils. The worst dielectric characteristics were measured on DBP oil. This oil moreover belongs to the oils purely destined for the industry application (due to the possibility of toxic waste products creation). The best properties of all synthetic oils were observed on DOA oil sample, this oil approximates in some aspects to the properties of petroleum-based oils. This result is very positive considering that DOA oil is biodegradable liquid. Despite of the good electrical properties and good thermal stability of DOA oil, its direct application as the insulating liquid is not presently recommended just for the lower oxidative stability of this oil. Suitable oxidation inhibitor could solve this problem; hence it will be (together with continuing thermal aging) the main aim of our further experiment.

\section{Acknowledgement}

This article was carried out by the help of Ministry of Education, Youth and Sports of Czech Republic, MSM 4977751310 - Diagnostics of Interactive Processes in Electrical Engineering.

\section{References}

[1] W.J., McNutt, R.L. Provost, R.J. Whearty, “Thermal life evaluation of high temperature insulation systems and hybrid insulation systems in mineral oil", Power Delivery, IEEE Transactions on Volume 11, Issue 3, Jul 1996 Page(s): 1391 - 1399.
[2] T. O. Rouse, "Mineral insulating oil in transformers", IEEE Electr. Insul.Mag., Vol. 14, No. 3, pp. 6-16, 1998.

[3] T. K. Saha, M. Darveniza, Z. T. Yao, D. J. T. Hill and G. Yeung, "Investigating the effects of oxidation and thermal degradation on electrical and chemical properties of power transformers insulation", IEEE Trans. Power Del., Vol. 14, pp. 1359-1367, 1999.

[4] M. I. Suwarno "Study on the Characteristics of Jatropha and Ricinnus Seed Oils as Liquid Insulating Materials“, IEEE CEIDP 2006, USA, pp. 162-165.

[5] I. L. Hosier, A. S. Vaughan and F. A. Montjen "Ageing of biodegradable oils for high voltage insulation systems“, IEEE CEIDP 2006, USA, pp. 481-484.

[6] C. Sun, J. Li, X. Li, S. Grzybowski "Electric Properties of Vegetable Oil-Based Dielectric Liquid and Lifetime Estimation of the Oil-Paper Insulation“, IEEE CEIDP 2006, USA, pp. 680-683.

[7] V. Mentlík, P. Trnka, J. Pihera, P. Prosr, "Electrical properties propagation of exposed combined insulation". In 16th IEEE International Conference on Dielectric Liquids ICDL 2008. New York : IEEE, 2008. pp. 365368. ISBN 978-1-4244-1586-1.

[8] V. Mentlík, P. Prosr, R. Polanský, “Aging of Petroleum and Synthetic Based Insulation Oils from the View of Structural Analyses". In 16th IEEE International Conference on Dielectric Liquids ICDL 2008. New York : IEEE, 2008. pp. 369-372. ISBN 978-1-4244-1586-1.

[9] V. Mentlík, P. Prosr, J. Pihera, R. Polanský, "New Possibilities of the Oil-paper Insulating Systems", 20th Nordic Insulation Symposium, pp. 157-160, ISBN 97882-519-2232-6, Jun 2007 Kgs. Lyngby, Denmark.

[10] P. Prosr, R. Polanský, J. Pihera, P. Trnka, "Influence of oil type on the oil-paper insulation properties". In 2007 Annual Report Conference on Electrical Insulation and Dielectric Phenomena. Vancouver : IEEE DEIS, 2007. pp. 77-80. ISBN 1-4244-1481-4.

[11] P. Trnka, J. Pihera, P. Prosr, R. Polanský, "Temperature Aging of the Selected Synthetic and Mineral Transformer Insulation Systems". In Annals of DAAAM for 2007 \& Proceedings of 18th International DAAAM Symposium. Vienna : DAAAM International Vienna, 2007. pp. 777-778. ISBN 3-901509-58-5. ISSN 1726-9679. 